\title{
Effects of 5,6-benzoflavone, indole-3-carbinol (I3C) and diindolylmethane (DIM) on chemically-induced mammary carcinogenesis: Is DIM a substitute for I3C?
}

\author{
RONALD A. LUBET ${ }^{1}$, BRANDY M. HECKMAN ${ }^{1}$, SILVIO L. DE FLORA ${ }^{3}$, VERNON E. STEELE ${ }^{1}$, \\ JAMES A. CROWELL ${ }^{2}$, M. MARGARET JULIANA ${ }^{4}$ and CLINTON J. GRUBBS ${ }^{4}$
}

Divisions of ${ }^{1}$ Cancer Prevention, ${ }^{2}$ Cancer Treatment and Diagnosis, National Cancer Institute, Bethesda, MD 20892,
USA; ${ }^{3}$ Department of Health Sciences, University of Genoa, Via A. Pastore 1, I-16132 Genoa, Italy;
${ }^{4}$ Chemoprevention Center, University of Alabama at Birmingham, Birmingham, AL 35294, USA

Received March 24, 2011; Accepted April 26, 2011

DOI: 10.3892/or.2011.1316

\begin{abstract}
The abilities of 5,6-benzoflavone (5,6-BF, a synthetic flavonoid), indole-3-carbinol (I3C, a plant derived product) or diindolylmethane (DIM, a condensation product of $\mathrm{I} 3 \mathrm{C}$ ) to alter the induction of mammary cancers induced by the carcinogens 7,12-dimethylbenzanthracene (DMBA) or $\mathrm{N}$-methyl-N-nitrosourea (MNU) were evaluated. Interestingly, the first two agents act as aryl hydrocarbon receptor (AhR) agonists, while DIM does not. The agents were initially examined for their ability to inhibit DMBA-induced mammary carcinogenesis. Agents were administered for 14 days starting 7 days prior to a single dose of the carcinogen. Evaluated over an extensive range of doses (165, 550 and $1650 \mathrm{ppm}$ in the diet), 5,6-BF caused a dose-dependent decrease of mammary cancers. In addition, 5,6-BF at doses of 1650 and $165 \mathrm{ppm}$ in the diet blocked the induction of DMBA-induced DNA adducts in the mammary gland by approximately $85 \%$ and $45 \%$, respectively. In contrast, DIM (180 or $20 \mathrm{mg} / \mathrm{kg}$ BW/day) failed to block induction of DMBA tumors. The effect of these agents on the promotion/progression phase of carcinogenesis using the MNU mammary cancer model was also determined. 5,6-BF (1650 or $165 \mathrm{ppm}$ in the diet), I3C (180 or $60 \mathrm{mg} / \mathrm{kg} \mathrm{BW/day}$ administered by gavage), or DIM (180 or $60 \mathrm{mg} / \mathrm{kg}$ BW/day by gavage) were initiated 5 days after the administration of MNU, and continually thereafter. 5,6-BF decreased MNUinduced mammary tumor multiplicity by $40-60 \%$. I3C reduced tumor multiplicity at the high dose, while DIM at either dose had minimal effects on tumor multiplicity. Thus, 5,6-BF and I3C were highly effective against initiation of DMBA-induced
\end{abstract}

Correspondence to: Dr Ronald A. Lubet, Division of Cancer Prevention, Executive Plaza North, Suite 2110, NIH, NCI, 9000 Rockville Pike, Bethesda, MD 20892, USA

E-mail: lubetr@mail.nih.gov

Key words: Ah receptors, 5,6-benzoflavone, indole-3-carbinol, diindolylmethane, mammary cancer mammary carcinogenesis, and were also effective against MNU-induced tumors during the promotion/progression phase of carcinogenesis. In contrast, DIM had minimal effects in either model; arguing that administration of DIM is not analogous to administration of I3C.

\section{Introduction}

5,6-benzoflavone $(5,6-\mathrm{BF})$ is a synthetic flavonoid that has been used for many years as a relatively non-toxic Ah receptor agonist. The compound binds to the Ah receptor (AhR) and induces transcriptional activation of a wide variety of phase I/ II drug metabolizing enzymes (1,2). 5,6-BF was examined as a potential chemopreventive agent as early as the mid 1970's, and proved to be capable of inhibiting 7,12-dimethylbenzanthracene (DMBA)-induced mammary, lung, and aflotoxin B1-induced hepatocarcinogenesis (3-5).

The plant product indole-3-carbinol (I3C) similarly activates the AhR, and is found at high levels in cruciferous plants. I3C has also been examined as a potential chemopreventive agent and has been shown to be effective in a wide variety of carcinogen-induced tumor models (6-9). It has been proposed that the efficacy of many of the so-called blocking agents, such as $5,6-\mathrm{BF}$ or $\mathrm{I} 3 \mathrm{C}$, on cancers initiated by procarcinogens (DMBA, aflatoxin, etc.) may be due to inhibition of the activation of carcinogens to their proximate moiety $(7,8)$. In agreement with this hypothesis, it has been shown that a number of agents that inhibit DMBA binding to DNA simultaneously inhibit DMBA-induced tumorigenesis (10-12). In addition to its effects in altering carcinogen metabolism, I3C has been shown to inhibit carcinogenesis in certain hormonally-related tumor models; e.g., mammary gland and endometrium of the uterus that do not involve carcinogen metabolism $(13,14)$. In fact, certain other AhR agonists have similarly been shown to affect direct-acting mammary carcinogens. Although the anti-tumor effects of these AhR agonists have been primarily attributed to altered metabolism of endogenous estrogens (i.e., estradiol), it has also been suggested that I3C or certain products resulting from breakdown or polymerization of I3C may have more direct anti-estrogenic effects (15-17). 
I3C is rapidly modified in the stomach to produce a wide variety of products including diindolylmethane (DIM). Although various condensation products, including indolo(3,2b)-carbazole, interact with the Ah receptor (18), DIM itself does not bind to this Ah receptor; but, nevertheless, has been shown to have antagonistic effects both with regards to the androgen and estrogen receptors $(17,19)$.

The specific objectives of the present studies were to determine: a) the dose response for 5,6-BF mediated inhibition of DMBA-induced mammary carcinogenesis, and its relationship to preventing formation of DMBA-related adducts in rat mammary epithelial cells; b) whether 5,6-BF, I3C and DIM can affect the tumor promotion/progression phase in the MNUinduced mammary cancer model; and c) if DIM, which is chemically stable, is a substitute for the potential chemopreventive effects of the chemically unstable I3C.

\section{Materials and methods}

Chemicals. DMBA, 5,6-BF and I3C were obtained from Sigma Chemical Co. (St. Louis, MO). DIM was obtained from The National Cancer Institute, Division of Cancer Prevention Repository. MNU was obtained from Ash Stevens (Detroit, MI).

Experimental animals. Female Sprague-Dawley rats were obtained from Harlan Sprague-Dawley, Inc. (virus-free colony number 205) at 4 weeks of age, and were placed on Teklad (4\%) diet. The rats were housed 5/cage in a room maintained at $22 \pm 2^{\circ} \mathrm{C}$ and artificially lighted $12 \mathrm{~h} /$ day. Animals were allowed free access to the diet and drinking water throughout the duration of the experiments. All animal experiments were conducted in facilities at the University of Alabama at Birmingham following the procedures approved by the Institutional Animal Care and Use Committee.

Preparations of various agents. I3C, which was found to be unstable in the diet, was administered by daily ( $7 \mathrm{x} /$ week) gavage. The compound was dissolved in degassed ethanol, and then mixed with corn oil to the appropriate dose level just prior to dosing the rats (gavage volume $=0.5 \mathrm{ml}$ ) $(20)$. The ratio of ethanol to corn oil was 40:60, v/v. DIM was prepared and administered using procedures identical to I3C, except the vehicle was ethanol:corn oil (10:90, v/v). 5,6-BF was mixed directly into the diet using a Patterson-Kelly blender with intensifier bar.

Treatment with various agents in the DMBA-induced model of mammary carcinogenesis. Animals were treated as previously described (20). In brief, rats were treated with the indicated levels of 5,6-BF (1650, 550 and $165 \mathrm{ppm}$ in diet), DIM (180 or $20 \mathrm{mg} / \mathrm{kg}$ BW/day by gavage), or I3C $(180 \mathrm{mg} / \mathrm{kg}$ BW/day) starting at 43 days of age. They were kept on these compounds until 57 days of age. Control animals were administered Teklad 4\% diet plus the appropriate vehicle. One week following the initiation of the treatments rats were administered DMBA (12 mg) by gavage (50 days of age). Rats were weighed weekly, palpated for mammary tumors twice per week, and checked daily for signs of toxicity. The studies were terminated approximately 4 months following DMBA administration. When the studies were terminated, mammary tumors were removed, and examined histopathologically.

Animals and treatments for DMBA adduct studies. Female Sprague-Dawley rats were obtained from Harlan SpragueDawley, Inc. and were housed as outlined above. Three groups of rats (5/group) were established as follows: group 1, DMBA; group 2, DMBA plus 5,6-BF (1650 mg/kg diet); group 3, DMBA plus $5,6-\mathrm{BF}(165 \mathrm{mg} / \mathrm{kg}$ diet). DMBA-treated rats received a single administration of the carcinogen by gavage $(12 \mathrm{mg} / \mathrm{kg}$ $\mathrm{BW})$ at 67 days of age. The 5,6-BF treated groups received the agent for 7 days before DMBA treatment. Rats were sacrificed by $\mathrm{CO}_{2}$ asphyxiation $48 \mathrm{~h}$ after DMBA administration. Mammary glands were rapidly removed and stored in liquid nitrogen (21).

DNA adduct analyses in rat mammary epithelial cells. The samples were shipped from the University of Alabama at Birmingham on dry ice to the University of Genoa, where they were immediately stored at $-80^{\circ} \mathrm{C}$. Fat-free mammary epithelial cells were prepared (22) and DNA adducts were examined as previously described (12).

Determination of levels of RNAs coding for liver phase I drug metabolizing enzymes. At 60 days of age, female SpragueDawley rats were treated with 5,6-BF (1650 ppm), DIM $(180 \mathrm{mg} / \mathrm{kg} \mathrm{BW})$ or vehicle for a period of 7 days. After 7 days, rats were sacrificed and the livers processed for use in microarrays as previously described $(23,24)$. The expressions of CYP 1A1 and CYP 1B1 were determined in the livers of all rats.

Treatment with various agents in the MNU-induced model of mammary carcinogenesis. Rats were housed as described above for the DMBA model. At 50 days of age, they were injected IV (via the jugular vein) with MNU (50 mg/kg BW) (20). Rats (15/group) were administered the doses of 5,6-BF (1650 or $165 \mathrm{ppm}$ in the diet), I3C (180 or $60 \mathrm{mg} / \mathrm{kg} \mathrm{BW/day}$ by gavage), or DIM (180 or $60 \mathrm{mg} / \mathrm{kg} \mathrm{BW} /$ day by gavage) beginning 5 days following the administration of $\mathrm{MNU}$ and continuing until the end of the study. Rats were weighed weekly, and palpated for mammary tumors twice per week. The studies were terminated approximately 4 months following MNU administration. All tumors were histologically classified.

Statistical analysis. Chemopreventive effects of I3C or 5,6-BF on mammary cancer incidence and latency were determined employing the log-rank analysis, while differences in cancer multiplicity were determined employing the Armitage test (25).

\section{Results}

Effects of agents on DMBA-induced mammary carcinogenesis. Rats were administered 5,6-BF in the diet or DIM by gavage beginning at 43 days of age and ending at 57 days of age (Fig. 2). At 50 days of age, rats were administered a single dose of the carcinogen DMBA. 5,6-BF caused a dose-dependent decrease in DMBA-induced mammary carcinogenesis (Fig. 2A). The highest dose of 5,6-BF (1650 ppm) profoundly inhibited DMBA-induced mammary carcinogenesis; however, 
<smiles>O=c1cc(-c2ccccc2)oc2ccc3ccccc3c12</smiles>

5, 6-Benzoflavone<smiles>OCc1c[nH]c2ccccc12</smiles>

Indole-3-Carbinol

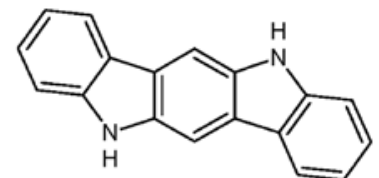

Indolo[3,2-b]carbazole

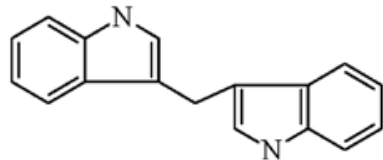

Diindolylmethane

Figure 1. Structures of agents.

Table I. Levels of DMBA ${ }^{32} \mathrm{P}$-post-labeled DNA adducts in mammary epithelial cells and effects of treatment with 5,6-benzoflavone.

\begin{tabular}{cccc}
\hline $\begin{array}{c}\text { Autoradiographic } \\
\text { spot }\end{array}$ & \multicolumn{3}{c}{ Adducts $/ 10^{8} /$ nucleotides } \\
& & $\begin{array}{c}\text { DMBA } \\
5,6-\mathrm{BF}\end{array}$ & $\begin{array}{c}\text { DMBA }+ \\
5,6-\mathrm{BF}\end{array}$ \\
& & $(1650 \mathrm{ppm})$ & $(165 \mathrm{ppm})$ \\
\hline 1 & $18.6 \pm 6.5$ & $2.7 \pm 1.2^{\mathrm{a}}$ & $10.3 \pm 3.7^{\mathrm{b}}$ \\
2 & $3.8 \pm 1.4$ & $0.8 \pm 0.8^{\mathrm{b}}$ & $2.5 \pm 0.9$ \\
3 & $2.4 \pm 1.3$ & $0.4 \pm 0.4^{\mathrm{a}}$ & $2.0 \pm 0.7$ \\
4 & $1.7 \pm 1.1$ & $0.3 \pm 0.2^{\mathrm{b}}$ & $1.2 \pm 0.9$ \\
5 & $3.2 \pm 1.9$ & $0.6 \pm 0.6^{\mathrm{a}}$ & $1.8 \pm 1.0$ \\
Total & $29.7 \pm 12.1$ & $4.9 \pm 3.0^{\mathrm{a}}$ & $16.6 \pm 9.2^{\mathrm{b}}$
\end{tabular}

DMBA $(12 \mathrm{mg} / \mathrm{kg}$ BW) administered once by gavage to female Sprague-Dawley rats. 5,6-BF administered in the diet. Values are mean $\pm \mathrm{SD} ; \mathrm{n}=5$. Duplicate analyses performed on each sample. ${ }^{\mathrm{a}} \mathrm{P}<0.01,{ }^{\mathrm{b}} \mathrm{P}<0.05$ compared to DMBA alone; Student's t-test for unpaired data.

even the low dose of 165 ppm inhibited formation of DMBAinduced mammary cancers by almost $50 \%$. In contrast, DIM failed to alter the induction of mammary tumorigenesis when given for this time period (Fig. 2B).

Effects of 5,6-BF treatment on levels of DMBA-DNA adducts in rat mammary epithelial cells. Levels of DMBA-DNA adducts were examined as previously described (12) in mammary epithelial cells by employing a ${ }^{32} \mathrm{P}$-post-labeling procedure; which has a sensitivity level of 0.1 adducts $/ 10^{8}$ nucleotides (Table I). Administration of a single dose of DMBA (12 mg/kg BW) by gavage resulted in the formation of multiple DNA adducts in mammary epithelial cells. The autoradiograph spots observed during ${ }^{32} \mathrm{P}$-post-labeling analyses likely were from reactions between anti-DMBA-dihydrodiol

A

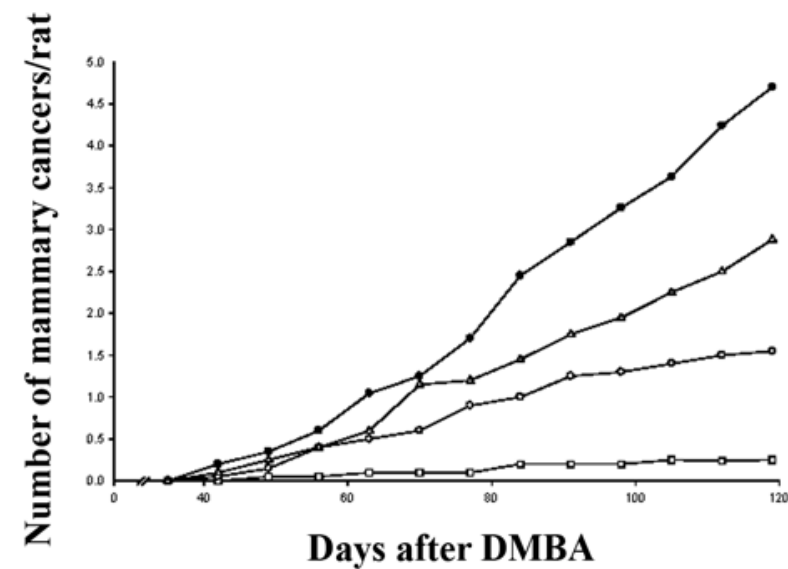

B

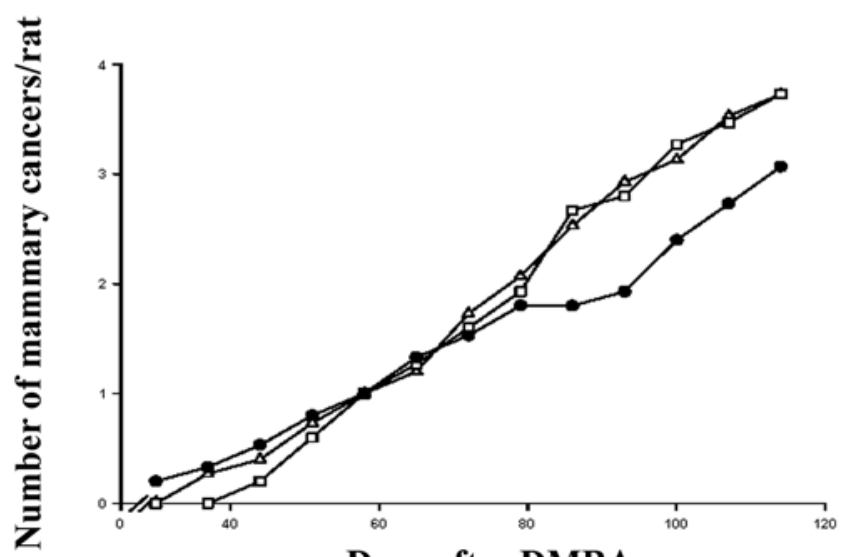

Days after DMBA

Figure 2. Effects of agents on the time of appearance of DMBA-induced mammary cancers in female Sprague-Dawley rats. (A), 5,6-benzoflavone: 口, $1650 \mathrm{ppm}$;, $550 \mathrm{ppm} ; \Delta, 165 \mathrm{ppm}$; $\bullet$, none. (B), Diindolymethane: $\Delta$, $180 \mathrm{mg} / \mathrm{kg} \mathrm{BW} / \mathrm{day} ;$ ㅁ, $20 \mathrm{mg} / \mathrm{kg}$ BW/day; $\bullet$, none.

epoxide and either $\mathrm{dG}$ (spots 1 and 5) or dA (spot 2), and between syn-DMBA-dihydrodiol epoxide and either dG (spot 3) or dA (spot 4) (25). Administration of 5,6-BF in the diet immediately prior to and following DMBA administration resulted in a significant and marked inhibition of all formed DNA adducts by approximately $85 \%$. The 5 autoradiographic spots were reduced by treatment with the chemopreventive agent to a similar extent; i.e., by $85.5,78.9,83.3,82.4$ and $81.3 \%$, respectively. Treatment of rats with $165 \mathrm{ppm} 5,6-\mathrm{BF}$ decreased overall DNA adduct formation roughly $45 \%$ and decreased the levels of individual adducts $40-50 \%$.

Effects of 5,6-BF or DIM on the induction of CYP $1 A 1$ and CYP $1 B 1$. The ability of 5,6-BF and DIM to induce CYP 1A1 and CYP 1B1 was examined (Fig. 3). As can be readily observed, the 5,6-BF (1650 ppm in the diet) profoundly induced the RNAs coding for both of these enzymes in the livers of treated rats. In contrast, DIM failed to induce levels of RNAs coding for the genes of either of these CYPs.

Effects of agents on MNU-induced mammary carcinogenesis. Rats were treated with 5,6-BF, I3C or DIM starting at 55 days 


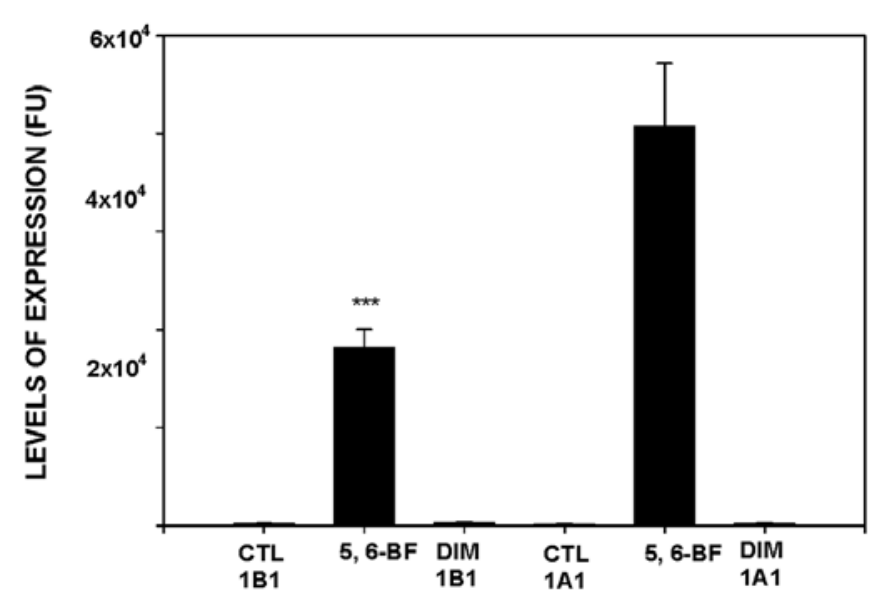

Figure 3. Induction of CYP $1 \mathrm{~A} 1$ and CYP $1 \mathrm{~B} 1$ in livers of rats treated shortterm (7 days) with 5,6-benzoflavone (1650 ppm) or diindolymethane $(180 \mathrm{mg} /$ $\mathrm{kg} \mathrm{BW}$ ). CTL, controls. RNA was isolated and processed as per Materials and methods.

of age; 5 days following treatment with MNU (Fig. 4). The higher dose (1650 ppm) of 5,6-BF decreased tumor multiplicity by $40 \%$. Interestingly, the lower dose of 5,6-BF (165 ppm) decreased tumor multiplicity by almost $50 \%$. At the higher dose of 5,6-BF, liver to body weight ratios increased approximately $20 \%$ (data not shown). I3C at $180 \mathrm{mg} / \mathrm{kg} \mathrm{BW} /$ day reduced tumor multiplicity by $65 \%$. The higher dose of I3C significantly increased liver to body weight ratios by $28 \%$. Finally, no significant effect on tumor multiplicity was observed in rats treated with either dose of DIM. These agents were examined for their effects on the estrus cycles of the rats. None of the agents altered estrus cycles.

\section{Discussion}

I3C is found at high levels in a variety of plants, while 5,6-BF is a synthetic product. Both of these agents or their metabolites are known to interact with the Ah receptor $(1,2,20,23)$. These compounds induce both phase I (oxidative, generally P450 mediated) and phase II (conjugation) drug metabolizing enzymes. When examining the CYP genes, 5,6-BF appears to be a typical 'dioxin type' inducer; increasing levels of the various CYP1 super family (e.g., CYP 1A1, CYP 1A2, and CYP 1B1), and actually decreasing activities of certain other CYP proteins (e.g., CYP 3A). In contrast, I3C is quite unusual since it induces the CYP1 superfamily as well as phenobarbital inducible CYPs 2B and 3A (20,27). Presumably, this dichotomy is due to the fact that certain of the condensation products [e.g., indolo(3,2-b)carbazole], rather than I3C itself, interact with the Ah receptor (19) while I3C mediates the phenobarbitallike response. In addition to inducing these CYP proteins, both of these compounds induce a wide range of phase II drug metabolizing enzymes (glutathione transferases, glucoronyl transferases, sulfotransferases, etc.) (20,27). Therefore, any attempt to determine the relative role of induction of CYPs, various conjugating enzymes, etc. in their ability to inhibit the efficacy of various pro-carcinogens is quite complex. Further complicating such an approach is the fact that these compounds, or their metabolites, are direct inhibitors of various purified

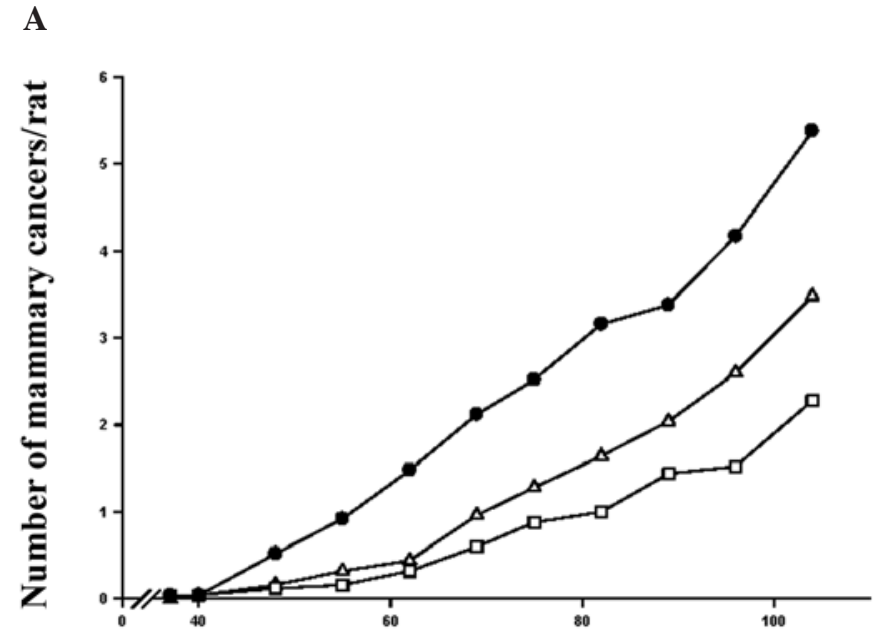

Days after MNU

B

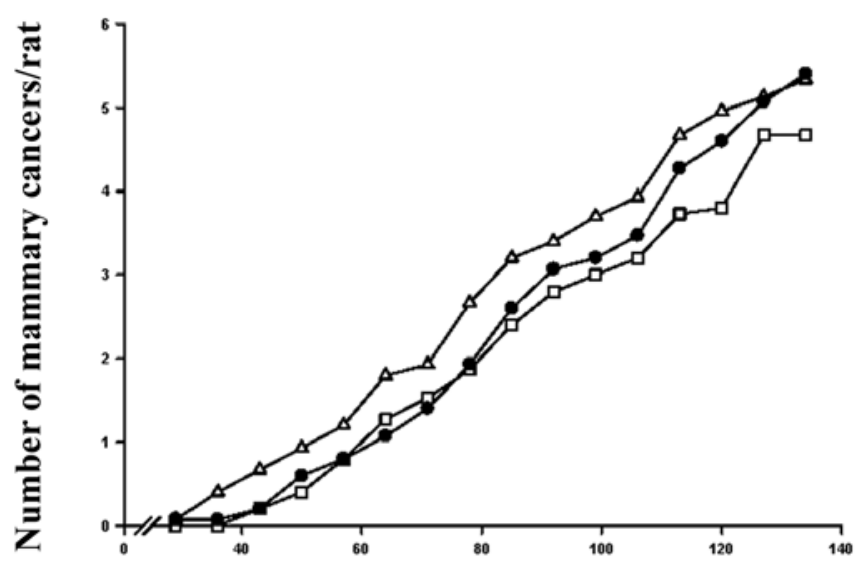

Days after MNU

C

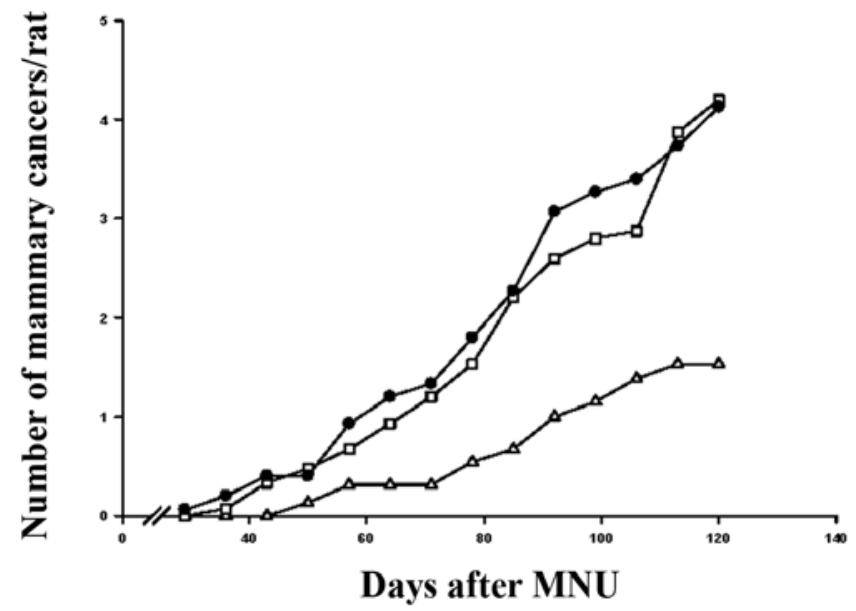

Figure 4. Effects of agents on the time of appearance of MNU-induced mammary cancers in female Sprague-Dawley rats. (A), 5,6-benzoflavone: $\triangle$, 1650 ppm; $\square, 165$ ppm; •, none. (B), Diindolymethane: $\square, 180 \mathrm{mg} / \mathrm{kg} \mathrm{BW/day;}$ $\triangle, 60 \mathrm{mg} / \mathrm{kg} \mathrm{BW} /$ day; $\bullet$ none. (C), Indole-3-carbinol: $\triangle, 180 \mathrm{mg} / \mathrm{kg} \mathrm{BW} /$ day; $\square, 60 \mathrm{mg} / \mathrm{kg} \mathrm{BW} /$ day; $\bullet$, none.

cytochromes P450s; including those cytochromes which they induce. In contrast, DIM failed to induce RNA coding for 
either CYP 1A1 or CYP 1B1. This is compatible with prior studies showing that DIM, unlike certain other I3C condensation products, was not an agonist for the Ah receptor $(17,27)$. Although at very high doses in cell culture, investigators have reported limited Ah receptor agonist activity (28).

5,6-BF has previously been evaluated in the DMBA-induced rat mammary tumor model. The studies of Wattenberg and Leong (3), reported almost 30 years ago, employed a single large dose of 5,6-BF while a recent study employed repeated gavage dosing (29). In a previous set of experiments (data not shown), we had examined relatively high, albeit non-toxic, doses of 5,6-BF (3300 and $1650 \mathrm{ppm}$ in the diet), and found both doses to be profoundly effective in reducing tumor formation $(>90 \%)$. The present experiments were designed to determine the dose response to $5,6-\mathrm{BF}$ and possibly a 'no effect' dose. Despite the fact that the dose of 5,6-BF was decreased x20 (3300 vs. $165 \mathrm{ppm}$ ), we failed to achieve an ineffective dose. In fact, almost a $50 \%$ decrease in tumor multiplicity at the lowest dose of 5,6-BF was still observed.

Interestingly, in the DMBA-induced rat mammary model mixed inducers such as 5,6-BF or I3C appear to optimally yield more striking effects than can be achieved with optimal doses of most of the relatively specific phase II inducers such as 1,2-dithiolthione or oltipraz (23). DIM, which does not interact with the Ah receptor and does not induce the various phase I and II drug metabolizing enzymes, failed to inhibit DMBA-induced mammary carcinogenesis. The general hypothesis has been that these alterations in DMBA-induced carcinogenesis are likely to reflect differences in DMBAinduced DNA damage in the target tissue $(7,8,12)$. Indeed, it was found that 5,6-BF (1650 and $165 \mathrm{ppm}$ ) decreased DMBAinduced DNA adducts in mammary epithelial tissue by 85 and $45 \%$, respectively. Thus, the efficacy of 5,6-BF and I3C in inhibiting DMBA-induced carcinogenesis is presumably associated with their interaction with the Ah receptor and their ability to induce various CYP genes as well as glutathione and UDP. UDP glucoronyl transferases are associated with their activity in this model.

As stated above, the fact that certain of the mixed inducers can alter carcinogen metabolism is no surprise. However, there has been evidence for a long time that certain of these agents can inhibit induction of hormonally-related cancers (breast, endometrial) independently of carcinogen metabolism $(13,14,20)$. We previously showed that $\mathrm{I} 3 \mathrm{C}$ decreased tumor multiplicity by $50-60 \%$ (20). One criticism of that work was that I3C was administered prior to the carcinogen. Therefore, in order to examine the effect of this chemopreventive agent on the promotion/progression phase of mammary carcinogenesis, we initiated chemopreventive treatment in the present study five days following MNU administration. Under these circumstances, the highest dose of I3C $(180 \mathrm{mg} / \mathrm{kg}$ BW/day) caused a $65 \%$ decrease in tumor multiplicity, while the lowest dose of I3C (60 mg/kg BW/day) had no effect. Interestingly, and somewhat unexpectedly, we did not find that treatment with DIM decreased MNU-induced mammary cancer formation. Prior results by Safe and coworkers (17) had found a substantial inhibitory effect of DIM when administered late in the DMBA model of tumorigenesis. Since tumors from both the DMBA model and the MNU model are primarily ER-positive and responsive to multiple hormonal agents, we had anticipated a decrease in mammary cancers. One difference is that Safe et al (17) used pure DIM, while we used a preparation that had certain inert components as well. Thus, we do not have a clear basis for the apparent discrepancy, but found this lack of efficacy in at least two studies. Finally, we examined the efficacy of I3C and DIM given in conjunction with a suboptimal dose of the SERM, tamoxifen (data not shown). Tamoxifen is approved for prevention of invasive breast cancer in postmenopausal women. We failed to observe any synergy between either of these agents and suboptimal dose of tamoxifen in agreement with the results of Malejka-Giganti et al (30).

To confirm the general applicability of the finding with indole-3-carbinol, the effects of 5,6-BF administered during the promotion/progression stage of MNU-induced mammary carcinogenesis was examined. Two doses of 5,6-BF were employed (1650 and $165 \mathrm{ppm}$ in the diet), and it was found that they reduced tumor multiplicity $40-60 \%$. There are a variety of possible mechanisms whereby $\mathrm{I} 3 \mathrm{C}, 5,6-\mathrm{BF}$, or related compounds which interact with the Ah receptor might accomplish their effects on mammary tumorigenesis. Bradlow et al (13), examining I3C, initially hypothesized that production of $2-\mathrm{OH}$-estradiol and decreased production of $16-\mathrm{OH}$-estradiol were associated with the preventive efficacy of these agents. However, besides being a relatively weak estrogen, 2-OH-estradiol serves as a precursor to 2-methoxyestradiol via O-methyltransferases, and this latter compound has both anti-angiogenic and anti-proliferative activities (16). In addition, Safe and coworkers (17) have shown that compounds which interact with the Ah receptor have some direct antagonistic effects with regard to the estrogen receptor; and may thereby block expression of various target genes which are themselves modulated by estrogen levels. In contrast to the efficacy of the Ah receptor agonists in both models, we failed to observe inhibition of tumors in either model treated with DIM. This demonstrates that although DIM may be the major condensation product of I3C, it does not appear to be the primary determinant of the efficacy of I3C.

Despite certain promising aspects of this class of compounds, a variety of questions still arise. First, there is the general fear that induction of phase I drug metabolizing enzymes may increase activation of certain carcinogens. Although clear evidence for this has been demonstrated for preferential activation of various carcinogens in vitro, the data with regards to increased activation in vivo have not been as convincing (30). In contrast, these agents have been effective in inhibiting carcinogenesis or DNA adduct formation by various carcinogens, including DMBA, aflatoxin B1, MEIQ, NNK and cigarette smoke. Second, I3C has proven to be a liver carcinogen, at least in rainbow trout (31). However, the extrapolation of hepatic carcinogenicity between species has been notoriously difficult. Despite these questions, this class of compounds appears to have significant efficacy in a variety of tumor models. The profound efficacy in many models that involve metabolism of pro-carcinogens warrants further investigation in chemoprevention models. Finally, the Ah receptor agonists have recently been shown to have efficacy in preventing colon cancer development. Their efficacy is based on the fact that the agonist-Ah receptor complex enhance the degradation of $\beta$-catenin. $\beta$-catenin accumulation is the major pathway by which truncating APC mutations enhance colon cancer (32). 


\section{Acknowledgements}

The authors wish to thank Jeanne Hale, Mary Jo Cagle and Julie Gray for editorial services. Also, thanks are expressed to Tom Morgan, Bonnie Dillon and Brittany Cornelius for assistance with the animal studies. This study was supported by NCI Master Agreements N01-CN-75008 and NO1-CN-43301.

\section{References}

1. Wattenberg LW, Page MA and Leong JL: Induction of increased benzopyrene hydroxylase activity by flavones and related compounds. Cancer Res 28: 934-937, 1968.

2. Boobis AR, Nebert DW and Felton JS: Comparison of $\beta$-naphthoflavone and 3-methylcholanthrene as inducers of hepatic cytochrome(s) P448 and aryl hydrocarbon(benzo[a]pyrene) hydroxylase activity. Mol Pharmacol 13: 259-268, 1977.

3. Wattenberg LW and Leong JL: Inhibition of the carcinogenic action of 7,12-dimethylbenzanthracene by beta-napthoflavone. Proc Soc Exp Biol Med 128: 940-943, 1968.

4. Diamond L, McFall R, Miller J and Gelboin HV: The effects of two isomeric benzoflavones on aryl hydrocarbon hydroxylase and the toxicity and carcinogenicity of polycyclic hydrocarbons. Cancer Res 32: 731-736, 1972.

5. Nixon JE, Hendricks JD, Pawlowski NE, Pereira CB, Sinnhuber RO and Bailey GS: Inhibition of aflatoxin B1 carcinogenesis in rainbow trout by flavone and indole compounds. Carcinogenesis 5: 615-619, 1984

6. Guo D, Schut HA, Davis CD, Synderwine EG, Bailey GS and Dashwood RH: Protection by chlorophyllin and indole-3-carbinol against 2-amino-1-methyl-6-phenylimidazo (4,5-b)pyridine ( $\mathrm{PhlP})$ induced DNA adducts and colonic aberrant crypts in the F344 rat. Carcinogenesis 16: 2391-2397, 1995.

7. Morse MA, La Greca SD, Amin SG and Chung FL: Effects of indole-3-carbinol on lung tumorigenesis and DNA methylation induced by 4-(methylnitrosamino)-1-(3-pyridyl)-1-butanone (NNK) and on the metabolism and disposition of NNK in $\mathrm{A} / \mathrm{J}$ mice. Cancer Res 50: 2613-2617, 1990.

8. Dashwood RH, Arbogast DN, Fong AT, Pereira C, Hendricks JD and Bailey GS: Quantitative interrelationship between aflatoxin B1 carcinogen dose, indole-3-carbinol anti-carcinogen dose, target organ DNA adduction and final tumor response. Carcinogenesis 1: $175-181,1989$.

9. Tanaka T, Kojima T, Morishita Y and Mori H: Inhibitory effects of the natural products indole-3-carbinol and singrin during initiation and promotion phases of 4-nitroquinoline 1-oxideinduced rat tongue carcinogenesis. Jpn J Cancer Res 83: 835-842, 1992.

10. Ip C, Vadhanavikit S and Ganther H: Cancer chemoprevention by aliphatic selenocyanates: effect of chain length on inhibition of mammary tumors and DMBA adducts. Carcinogenesis 16: 35-38, 1995.

11. Singletary KW, MacDonald C and Wallig M: The plasticizer benzyl butyl phthalate (BBP) inhibits 7,12-dimethylbenz[a] anthracene (DMBA)-induced rat mammary DNA adduct formation and tumorigenesis. Carcinogenesis 18: 1669-1973, 1997.

12. Izzotti A, Camoirano A, Cartiglia C, et al: Patterns of DNA adduct formation in liver. Cancer Res 59: 4285-4290, 1999.

13. Bradlow HL, Minchovicz JJ, Telang NT and Osborne MP: Effects of dietary indole-3-carbinol on estradiol metabolism and spontaneous mammary tumors in mice. Carcinogenesis 12 : $1571-1574,1991$.
14. Kojima T, Tanaka T and Mori H: Chemoprevention of spontaneous endometrial cancer in female Donryu rats by dietary indole-3carbinol. Cancer Res 54: 1446-1449, 1994.

15. Martucci CP and Fishman J: P450 enzymes of estrogen metabolism. Pharmacol Ther 57: 237-257, 1993.

16. Zhu BT and Conney AH: Is 2-methoxyestradiol an endogenous estrogen metabolite that inhibits mammary carcinogenesis. Cancer Res 58: 2269-2277, 1998.

17. Chen I, McDougal A, Wang F and Safe S: Aryl hydrocarbon receptor-mediated antiestrogenic and antitumorigenic activity of diindolylmethane. Carcinogenesis 19: 1631-1639, 1998.

18. Bjeldanes LF, Kim JY, Grose KR, Bartholomew JC and Bradfield CA: Aromatic hydrocarbon responsiveness-receptor agonists generated from indole-3-carbinol in vitro and in vivo: comparisons with 2,3,7,8-tetrachlorodibnezo-p-dioxin. Proc Natl Acad Sci USA 88: 2543-2547, 1993.

19. Le HT, Schaldach C, Firestone GL and Bjeldanes LF: Plantderived 3,1'-diindolylmethane is a strong androgen antagonist in human prostate cancer cells. J Biol Chem 278: 21136-21145, 2003.

20. Grubbs CJ, Steele VE and Casebolt T: Chemoprevention of chemically-induced mammary carcinogenesis by indole-3-carbinol. Anticancer Res 15: 709-716, 1995.

21. Reddy MV and Randerath K: Nuclease P1-mediated enhancement of sensitivity of ${ }^{32} \mathrm{P}$-post-labeling test for structurally diverse DNA adducts. Carcinogenesis 7: 1543-1551, 1996.

22. Izzotti A, D'Agostini F, Bagnasco M, et al: Chemoprevention of carcinogen-DNA adducts and chronic degenerative diseases. Cancer Res 54: 1994S-1998S, 1994.

23. Gupta RC: Enhanced sensitivity of ${ }^{32} \mathrm{P}$-post-labeling analysis of aromatic carcinogen: DNA adducts. Cancer Res 45: 5656-5662, 1985.

24. Lubet RA, Yao R, Grubbs CJ, You M and Wang Y: Induced expression of drug metabolizing enzymes by preventive agents: role of the antioxidant response element. Chem Biol Interact 182: 22-28, 2009.

25. Armitage P: The chi square test for heterogeneity of proportion after adjusting for stratification. J R Stat Soc B 28: 150-163, 1966.

26. Vericat JA, Cheng SC and Dipple A: Absolute stereochemistry of the major 7,12-dimethylbenz[alpha]anthracene-DNA adducts formed in mouse cells. Carcinogenesis 10: 567-570, 1989.

27. Wortelboer HM, van der Linden EC, De Kruif CA, et al: Effects of indole-3-carbinol on biotransformation enzymes in the rat: in vivo changes in liver and small intestinal mucosa in comparison with primary rat hepatocyte cultures. Food Chem Toxicol 30: 589-599, 1992.

28. Chen I, Safe S and Bjeldanes L: Indole-3-carbinol and diindolylmethane as aryl hydrocarbon (Ah) receptor agonists and antagonists in T47D human breast cancer cells. Biochem Pharmacol 51: 1069-1076, 1996

29. Malejka-Giganti D, Benett K, Culp SJ and Beland RA: Metabolic aspects of inhibition by 5,6-benzoflavone on mammary tumorigenesis in the rat. Proc Am Assoc Cancer Res 37: 265, 1996.

30. Parkinson A and Hurwitz A: Omeprazole and the induction of human cytochrome P450: a response to concerns about potential adverse effects. Gastroenterology 100: 1157-1164, 1991.

31. Bailey GS, Hendericks JD, Shelton DW, Nixon JE and Pawlowski NE: Enhancement of carcinogenesis by the natural anticarcinogen indole-3-carbinol. J Natl Cancer Inst 78: 931-934, 1987.

32. Kawajiri K, Kobayashi Y, Ohtake F, et al: Aryl hydrocarbon receptor suppresses intestinal carcinogenesis in ApcMin/+ mice with natural ligands. Proc Natl Acad Sci USA 106: 13481-13486, 2009. 